\title{
EL ENSAYO HISPANOAMERICANO, DEL MODERNISMO A LA MODERNIDAD
}

POR

PETER G. EARLE

University of Pennsylvania

En tres etapas se desarrolló el ensayo hispanoamericano: la primera, romántica; la segunda, simbolista; la tercera, de vanguardia.

En la primera se exalta al individuo en su función orgánica (Bello, Echeverría, Sarmiento, Montalvo). Biología espiritual; los escritores se entusiasman por las fuerzas que animan al hombre y a la naturaleza: la sombra de Facundo recobrada por Sarmiento, el espectro de Bolívar al lado de Montalvo, el mundo potente que nace en las escenas de Martí.

En la segunda se quiere objetivar la belleza, revelarla en pausadas epifanías: el velo azul de los sueños de Rubén Darío; el descenso órfico del protagonista de Sangre patricia; Próspero, el de Rodó, en su castillo interior. Morada estética, defensa continua de la Poesía. Pero en este período (1880-1920), el ensayo encuentra su base en la historia y en el pensamiento sobre el significado múltiple del Nuevo Mundo. Surgió, al menos como punto inevitable de referencia, del Positivismo, y en muchos sentidos reaccionó contra él.

En la tercera, a partir de 1920, la literatura será conocimiento. Vanguardia, para los ensayistas iberoamericanos, será el ejercicio de una epistemología. Las lecciones, en parte utópicas, de Alfonso Reyes, Pedro Henríquez Ureña y José Vasconcelos se seguirán leyendo cuando los cultos poéticos de los años veinte hayan pasado de moda. Las metáforas se vuelven oximorónicas; «la espera es eterna: anula al tiempo; la espera es instantánea: está al acecho de lo inminente», afirma Octavio Paz en El mono gramático. Se nos instruye en el escepticismo; la armonía de las esferas será sustituida por cualquier paradoja.

La riqueza del Modernismo es evidente en su calidad de transición: asimila las fuerzas naturales del Romanticismo y la luminosidad y la pulcritud sincrética del Simbolismo; y la confrontación entre la idealidad 
estética de Darío, Rodó y Díaz Rodríguez y el mundo cotidiano conduce a la visión irónica no sólo de la Vanguardia de los años veinte, sino del ensayo de nuestro siglo. Muchas veces se ha querido formar una impresión aristocrática del Modernismo, negando así su esencial heterogeneidad, y dentro de esa heterogeneidad, el deseo de una nueva armonía, emblema de una nueva autonomía. El artista no es aristocrático; es independiente.

El motivo del Modernismo, como de todo movimiento literario fecundo, fue el deseo de una doble liberación: artística e intelectual. El Modernismo no fue portavoz ni expresión indirecta de la burguesía, ni del proletariado, ni de aristocracia alguna. El juicio de Arthur Symons en The Symbolist Movement in Literature (1. ${ }^{a}$ ed., 1899) puede aplicarse a las literaturas americanas de la misma época:

The artist, it cannot be too clearly understood, has no more part in society than a monk in domestic life: he cannot be judged by its rules, he can be neither praisea nor blamed for his acceptance or rejection of its conventions. Social rules are made by normal people for normal people, and the man of genius is fundamentally abnormal ${ }^{1}$.

La expresión literaria no representa ideologías ni realidades históricas ni estructuras o superestructuras sociales. Más bien refleja o responde a ellas, así como refleja o responde a muchos otros fenómenos: religiosos, económicos, psicológicos, culturales o gástricos. La elaboración del ensayo no implica mayor ni menor compromiso social que la de cualquier otra forma. En el mejor de los casos, el ensayo no es discurso, ni teoría, ni comentario, ni satélite de otros géneros, sino expansión y desarrollo de un estímulo lírico. Todo ensayista que valga es poeta en prosa.

Los Contemporáneos mexicanos nacieron para la poesía - según José Gorostiza- «bajo el signo gigante del Modernismo» («Notas sobre poesía", en Poesía, 2. ${ }^{a}$ ed., México, 1971). La luz modernista reverberaba

${ }^{1}$ En su breve vida Julio Herrera y Reissig cumplió ese ideal independentista. Desde su «Torre de las Panoramas» de la casa paterna en Montevideo, el joven poeta respondió a los crueles ataques a sus primeras poesías con un «Decreto»:

«Abomino la promiscuidad del catálogo. iSolo y conmigo mismo! Proclamo la inmunidad literaria de mi persona.

Ego stm imperator. Me incomoda que ciertos peluqueros de la crítica me hagan la barba...

¡Dejad en paz a los Dioses!

Yo, Julio.»

(Citado por Alfred Coester en su Anthology of the Modernista Movement in Spanish America, Boston, 1924, p. 299.) 
todavía en la tercera década de este siglo cuando los Contemporáneos, «grupo sin grupo», juntaron sus soledades y preocupaciones en torno a una revista. Y fue Gorostiza quien con frase feliz captó el espíritu de la generación precedente. E1 Modernismo, ¿qué fue en su idolatría de la forma sino una verdadera orgía de musicalidad?».

Para la mayoría de los escritores y la crítica dominante de su tiempo, musicalidad y forma - casi se diría estatuaria y arquitectura- eran los dos polos del arte literario. Si es cierto que la crítica perspicaz desde entonces ha querido ver en la forma y la musicalidad modernistas un punto de partida más que una idolatría, también es cierto que, en el nivel creador consciente, forma importada más que lenguaje o pensamiento. Esto no significa que los modernistas, más que las generaciones anteriores o las posteriores, hayan precisado su sistema expresivo. Si significa que buscaban con mayor afán los signos de su idealidad estética: la «Amazona emblemática» de Julio Herrera y Reissig, los pulidos paisajes simbólicos de José Enrique Rodó. La búsqueda revela al mismo tiempo confianza creadora e inseguridad intelectual. Creo que aquella inseguridad y confianza es evidente en la variedad de estructuras en que el esquema, el símbolo o la impresión sensible vale más que la totalidad orgánica. El Modernismo amaba el poema breve, la crónica, la divagación, el cuento (azul o dorado o color de humo), la silueta o la sensación, la escena (norteamericana o parisiense), la parábola o el motivo. La época iniciada por José Martí y Manuel Gutiérrez Nájera y llevada a su culminación por Rubén Darío no dejó obras «definitivas» ni en verso ni en prosa. La fuerza y potencialidad del Modernismo está en su actitud, en su mística de la Belleza, en lo luminoso de su simbolismo y en su modo oblicuo de ver las cosas y de transformarlas en sueños y resplandores. Todo poema y todo ensayo modernista es en alguna medida un esfuerzo por lograr la síntesis soñada de Baudelaire, en que «los perfumes, los colores y los sonidos se corresponden» («Correspondances», Les Fleurs du mal). En esas correspondencias lo primordial es la impresión no sólo para la breve poesía o el ensayo o cuento casual, sino para creaciones de estilo tan prolijo como la novela Sangre patricia o el ensayo Ariel. E1 arte modernista deja pendiente toda plenitud, borrosos los retratos, refinada la visión, reducido el cosmos, disminuida la persona. Entre sus practicantes, sólo Martí y Darío, y en menor grado Amado Nervo, hacen sentir la fuerza humana que los conmueve. Las letras hispanoamericanas de la época ofrecen tentativas más que obras; Ariel fue una gran tentativa: menos una vida que un recetario espiritual; consejos para cumplir algún día. Esas tentativas sustituyen el preludio amplio y disperso, se podría decir, a una gran literatura posible; y aunque el amor a la imagen per- 
dura mucho después de la muerte de Darío, resulta particularmente erróneo aludir a un período "posmodernista» en Hispanoamérica, pues más bien los simbolistas americanos preparan caminos. Introducen una nueva literatura americana y lo que sigue no es epílogo ni secuela, sino desarrollo de lo principal. Así, de la fantasía de Lugones se pasa a la epistemología de Borges, y de las abstractas idealizaciones de Rodó al escepticismo histórico (concreto) de Martínez Estrada y de Paz. El Modernismo predomina entre 1880 y 1920 porque la actitud de esperanza de la mayor parte de sus escritores se lo permiten. Son poetas y ensayistas en busca de visiones, no de realidades; profetas convencidos de que la transformación de éstas habían de cumplirse mediante la transformación de aquéllas. Los mejores momentos de Darío, de Rodó o de Martí insinúan una nueva movilidad visual, liberación del casticismo hispano, dulces evocaciones mitológicas y un feliz menage à trois entre el color, la música y la palabra.

Encuentro tres motivos esenciales en el ensayo hispanoamericano modernista que podrían ayudarnos a comprender su sentido de la forma; motivos que, a través del deseo ya señalado de objetivar la belleza, también son fines, ideales: 1) La autocontemplación o el ideal romántico. 2) La independencia del arte o el ideal clásico. 3) La misión cultural o el ideal histórico.

Primer motivo: La forma modernista es comprensible en el contexto del culto de la autocontemplación. Al comentar a los poetas simbolistas, Henri Peyre alude a la escasa importancia (para ellos) de la verdad objetiva. De Paul Verlaine, el poeta predilecto de Darío, dice:

His power of expression and of music was such that he could produce an impression of utter sincerity on his reader. His naiveté was deliberate. His sincerity was to portray himself as he thought he was, substituting in the process an authentic literary personality for the vacillating, childish, ... calculating and mendacious personality that he was ${ }^{2}$.

Es la inevitable mirada de Narciso que descubre al otro yo. Poe se encuentra en Israfel, Huysmans en Des Esseintes, Rodó en Próspero, Díaz Rodríguez en Tulio Arcos. El otro yo es el primer paso, y tal vez el decisivo, hacia la consumación modernista de la forma. En las figuras imaginadas por cada escritor - la estatua, el fantasma, el templo de arte de columnas dóricas, el cisne, la ola marina o la mirada de una emperatriz- se refleja algo de su ser, una cristalización parcial de sí mismo.

\footnotetext{
${ }^{2}$ Literature and Society (New Haven: Yale University Press, 1963).
} 
Esas figuras no son miméticas o representativas de una realidad, sino expresivas de una sensibilidad particular, la del artista verbal en calidad de querer-ser. José Enrique Rodó, de quien se podría decir como dijo Arthur Symons de Walter Pater: «He did not permit life to come to him without a certain ceremony» (Studies in Prose and Verse, London, 1905), nos describe una «misteriosa sala» del rey hospitalario en Ariel. La sala no es más ni menos que el alma del autor no en espera de salvación, sino en trance del goce estético y sensual:

Nunca reinó tan honda paz; ni en oceánica gruta, ni en soledad nemorosa... En el ambiente flotaba como una onda indisipable la casta esencia del nenúfar, el perfume sugeridor del adormecimiento penseroso y de la contemplación del propio ser... En los testeros, esculpidas imágenes hablaban de la idealidad, de ensimismamiento, de reposo...

Rubén Darío, a quien Enrique Anderson Imbert nos ha mostrado ser tan grande prosista como poeta (La originalidad de Rubén Dario, Buenos Aires, 1967), escribe un retrato trascendente del papa León XIII en octubre de 1900. El retrato, pequeña joya en sí, también sirve de introito a dulces recuerdos infantiles: "Viví por un momento en un mundo de recuerdos. Era la infancia de músicas y rosas, la lejana infancia en que el alma nueva y libre parecía volar ágil como un pájaro de encanto entre los árboles del Paraíso» («Roma», en Peregrinaciones). Por lo general, en Darío las notas autobiográficas son más actuales e inseparables de su culto a la belleza: «A la Belleza en general y a la femenina belleza en particular, y la continua tendencia a la vida con sus países de ensueño y sus realidades armoniosas, productoras, floreales, genésicas. Va ese gran placer del sensitivo que toca los nervios del mundo y los siente vibrar al unísono con sus nervios...» («Florencia», en Tierras solares).

Darío, en común con Martí, Rodó y aun con Unamuno, tiene un yo excepcionalmente expansivo. Ese yo aspiraba a dar a la realidad nuevas formas y energías que reflejarían siempre — del mismo yo- su dinamismo espiritual:

He meditado el problema de la existencia y he procurado ir hacia la más alta idealidad. He expresado lo expresable de mi alma y he querido penetrar en el alma de los demás, y hundirme en la vasta alma universal. He apartado asimismo, como quiere Schopenhauer, mi individualidad del resto del mundo, y he visto con desinterés lo que a mi yo parece extraño para convencerme de que nada es extraño a mi yo. He cantado en mis diferentes modos el espectáculo mul- 
tiforme de la naturaleza y su inmenso misterio. He celebrado el heroísmo, las épocas bellas de la historia, los poetas, los ensueños, las esperanzas. He impuesto al instrumento lírico mi voluntad del momento, siendo a mi vez órgano de los instantes, vario y variable, según la dirección que imprime el implacable destino («Dilucidaciones», en $E l$ canto errante).

Ya en 1905 el joven Pedro Henríquez Ureña capta la escencia autobiográfica de Ariel al referirse al culto griego «de las cosas elevadas y bellas que da el sentimiento superior de la Vida, definida por el Don Juan filósofo de Bernard Shaw como "la fuerza que lucha siempre por alcanzar mayor poder de contemplarse a sí misma'».

Segundo motivo: Evidente complemento del primero es la lucha por la independencia del arte. La mayor distinción entre la perspectiva literaria de hoy (crepúsculo de la modernidad) y la del Modernismo se halla en la armonía cósmica de ésta y en la perplejidad e inquietud de aquélla. A partir de «El rey burgués» de Rubén Darío, la intelectualidad hispanoamericana anhela una autonomía vital para las letras. En ese cuentoensayo o ensayo-narrativo de $A z u l$ se proclama la conciencia artística de ser diferente. La sociedad burguesa aparta, menosprecia y rechaza al poeta. E1 Rey Burgués 1lena su palacio de maravillosos objetos de arte, pero «por lujo y nada más». El rey burgués de Darío, como después el Calibán de Rodó y el escritor y académico Don Perfecto Beocio y Filisteo (seudónimo: Don Perfecto Nadie) de Díaz Rodríguez, son la cosificación de la cultura y la muerte de la espiritualidad en las letras. El deseo de los modernistas no es sólo devolver a las artes su merecido prestigio, sino situarlas en su clásico pedestal del bien supremo. Independencia significa no depender de los filisteos, pero más que eso exige la intervención del arte en todo lo que afecte a sociedad y cultura. La forma - plástica o literaria o arquitectónica- no tiene sentido alguno si no encierra una idealidad. En eso se distingue la forma (de funcionamiento siempre estético) del objeto (limitado a su propia utilidad). Kosmos, en griego, quería decir no sólo el universo, sino su inherente belleza. Para los principales modernistas, arte y poesía eran revelación más que creación. Y lo que había que revelar era la magnitud y belleza del universo: grande por bello y bello por grande. Se trataba de un acercamiento religioso. Manuel Díaz Rodríguez, entusiasta lector del De Profundis (1905) de Oscar Wilde, repite en su propio Camino de perfección el lema de éste: «The Mystical in Art, the Mystical in Life, the Mystical in Nature.» La religiosidad de Díaz Rodríguez, como la de Gutiérrez Nájera, Martí, Darío y Rodó, fue en parte cristiana, en parte olímpica y en parte pan- 
teísta. En su «Paréntesis modernista», de Camino de perfección, el autor señala dos tendencias representativas de la época: la de «volver a la naturaleza» y la del misticismo. Para Díaz Rodríguez, «las épocas de feliz renovación» del arte coinciden con un despertar del sentimiento religioso. En el contexto estético, la religiosidad de estos escritores fue un procedimiento simbolista. En la naturaleza se percibía el universo y en el universo la divinidad. Pero la divinidad era, ante todo, metáfora de la Belleza.

Mucho antes que Díaz Rodríguez, ya en una serie de cinco ensayos («E1 arte y el materialismo») publicados en 1876, Manuel Gutiérrez Nájera se estableció como primer preceptor panteísta del Modernismo. El paisaje que sigue es del segundo ensayo:

Lo bello es la representación de lo finito en infinito; la manifestación de lo extensivo en lo intensivo; el reflejo de lo absoluto; la revelación de Dios... Lo bello tiene que ser necesariamente ontológico: es lo absoluto, es Dios. Dios, que se revela en las sublimes creaciones del poeta, en las dulces melodías de la música, en los lienzos que con magnífico pincel traza el artista, y en las gigantescas moles que levanta el genio creador del arquitecto. Valiéndonos de una fórmula matemática, pudiéramos decir que la belleza es al artista como la perfección espiritual es al santo; el anhelado término, la suprema recompensa, la idea sublime.

La idea de la independencia del arte se fundó en ese centralismo espiritual. Los modernistas no dejaron de oír la música de las esferas ni de ver remotas simetrías. La calidad de lo incompleto a que me he referido (tentativas, fragmentos e impresiones más que obras) fue un hecho genérico y estilístico. Pero lo unitivo, la armonía y el sentido de totalidad constituían el ideal desde Martí y Gutiérrez Nájera hasta la generación formada en torno al simbólico Ateneo de la Juventud en México: Pedro Henríquez Ureña, José Vasconcelos, Alfonso Reyes: tres buscadores de la Armonía, escritores que prolongaban indirectamente la visión arielista.

Tercer motivo: Finalmente, el Modernismo fue una misión cultural, una tarea ideológica que cumplir en la historia hispanoamericana. Para Federico de Onís, el Renacimiento en España y el Modernismo fueron épocas decisivas, «una al principio y otra al fin de la Edad Moderna», en que la cultura hispánica llegó a imprimir «Carácter propio a un movimiento universal» ${ }^{3}$. Onís afirma que la originalidad se nutre de la co-

${ }^{3}$ España en América (Universidad de Puerto Rico, 1955). Parece que Onís confundía la Edad Moderna con el Modernismo hispánico, tratando de encerrar aquélla en éste. 
municación y no del aislamiento; a eso se puede añadir que España en el siglo XVI, como Hispanoamérica a fines del siglo XIX y a principios del $\mathrm{xx}$, iniciaba en forma concentrada el arduo proceso del autoconocimiento, y que ambas lograron situarse en el panorama histórico del mundo de tal manera que desde aquellos momentos la cultura y literatura propias constituyesen parte de la cultura y literatura mundiales.

Pero los ensayos hispanoamericanos estimulados por el Simbolismo tenían más de visión que de testimonio. Trataban de su época sólo indirectamente, a través de alguna imagen del porvenir. "A nuevos estados de alma, nuevas formas de expresión», escribía Pedro Emilio Coll en «Decadentismo y americanismo» (El castillo de Elsinor, Caracas, 1901). «Nuestra América» y «Walt Whitman» de Martí, «Dilucidaciones» (el vibrante prólogo - ya citado- de Darío a su Canto errante), Ariel y los Motivos de Proteo de Rodó) son afirmaciones de fe histórica. Para ellos, el futuro formaba un hermoso marco al presente. Los ensayistas de entonces, en sus mejores momentos, poetas, se sentían profetas. La poesía - dice Martí en «Walt Whitman»- crearía libertad, y la libertad pondría "alas a la ostra». El profeta de Leaves of Grass fue aliento y ejemplo heroico para el profeta de "Nuestra América», estímulo para que la intelectualidad hispanoamericana iniciara una nueva edad histórica:

No de rimillas se trata o de dolores de alcoba, sino del nacimiento de una era, del alba de la religión definitiva y de la renovación del hombre; trátase de una fe que ha de sustituir a la que ha muerto y surge con claror radioso de la arrogante paz del hombre redimido («Walt Whitman», en El Partido Liberal, México, 1887).

Los grandes ensayistas modernistas hicieron a través de su suave descontento una pregunta ante el porvenir: ¿cuándo nacería de nuevo la Edad de Oro? Los objetos del mundo inmediato, reflejos de una precaria realidad, cedieron el paso a las formas idealizadas, símbolos de lo posible. El simbolismo americano se distingue del movimiento simbolista en Francia e Inglaterra por su persistente orientación hacia el porvenir, en donde se encuentra la belleza y la libertad; la cultura americana está por hacer. Martí, a quien Martínez Estrada ha caracterizado como el último de los «grandes hombres» americanos (Martí, revolucionario, La Habana, 1967), expresaba a través de su obra un sueño unitivo que poco después de su muerte había de desvanecer. De haber vivido hoy hubiera escrito de nuevo lo que escribió en 1890: «Se probó el odio, y los países venían cada año a menos.» De los grandes ensayistas, ninguno pretendía que la estatua, el fantasma, el templo de arte, el cisne, la ola marina o la 
mirada de una emperatriz fuese la expresión última de su sensibilidad. Eran imágenes que creaban formas; es decir, ideas en germen de lo bello.

El Modernismo sobrevivió un poco. El tránsito entre él y la Vanguardia se entiende en el sincretismo compartido. Es decir, mientras que el Modernismo reanimó la antigua lucha entre arte y filosofía -favoreciendo, claro, al primero- también profesaba una conciliación. Al mismo tiempo que celebraba el Arte, sintetizaba las artes (las sincretizaba) e intentó subyugar a la religión y la filosofía, transformándolas en instrumentos para un continuo descubrimiento de la Belleza. La falacia fundamental del arielismo, que purificó la religión, la cultura y la filosofía en nombre del «Ideal», está en su obstinada abstracción. En su Estética (Vorlesungen über die Aesthetik, 1835), Hegel demuestra la necesidad de conciliar dos proposiciones opuestas: 1) «El arte forma parte del mundo», y 2) «El arte constituye un mundo propio». En general, los modernistas desconocieron ese equilibrio, pues quisieron excluir la realidad en que les tocó nacer para cultivar mejor sus ensueños. Pero su arte se hizo por su misma autonomía cada vez más abstracto. Para la hora en que Enrique González Martínez empezaba a torcerle el cuello al Cisne ya se iba marchitando la mayor parte de las creaciones modernistas. Por su arquitectura altruista y sus castas alegorías, Ariel y muchos de los Motivos de Proteo son la destilación última del ensayo modernista. Por consiguiente, los ensayos de la época, de la llamada Decadencia, dejaron de existir, no por morbosos ni por carecer de conceptos, sino por falta de sustancia.

¿Y después? Mucho después Alfonso Reyes se haría la pregunta (Ultima Tule, 1942), ya implícita en diversos ensayos historicistas: «¿Qué haremos en América?» Por supuesto, el contexto en que Reyes expresa la frase en 1942 es exótico en «la primavera de sueños» vivida por poetas y prosistas del siglo XvI. No por eso deja de tener vigencia. Alcides Arguedas se la hace, en efecto, en su desolador Pueblo enfermo (1909), anticipando con su visión de la meseta boliviana («allí no se sorprende la vida, sino la nada»), la de la pampa argentina de Martínez Estrada en Radiografía de la pampa (1933). Se la hace Pedro Henríquez Ureña en sus Seis ensayos en busca de nuestra expresión (1928), como José Vasconcelos en La raza cósmica (1925), José Carlos Mariátegui en Siete ensayos de interpretación sobre la realidad peruana (1928); después vendrán Eduardo Mallea, Historia de una pasión argentina (1937); El laberinto de la soledad (1950) y Posdata (1969), de Octavio Paz, y El pecado original de América (1954), de H. A. Murena.

«¿Qué haremos con América?» También había sido el interrogante de Martí, de Rodó y de Manuel González Prada en sus Páginas libres 
(1894). Pero con el advenimiento de la Modernidad, los valores positivos se adulteran. Rodó trataba de reducir $\longrightarrow$ o de condensar- la moral en una «estética de la conducta», y Mariano Picón Salas, con su sensible autobiografía (Regreso de tres mundos, 1959), en cierto modo repite ese esfuerzo. Sin embargo, la mayoría de los ensayistas funde lo ético con lo estético. El absolutismo esperanzado de los años noventa y de la primera década del nuevo siglo es sustituido por el relativismo pesimista de los nuevos (modernos). La nueva conciencia crítica ahuyenta a las ilusiones, los goces simbólicos y el paraíso; se vive una dispersión. La técnica misma, según Octavio Paz, es un símbolo central de la Modernidad.

Si el mundo, como imagen, se desvanece, una nueva realidad cubre toda la tierra. La técnica es una realidad tan poderosamente real - visible, palpable, audible, ubicua-, que la verdadera realidad ha dejado de ser natural o sobrenatural: la industria es nuestro paisaje, nuestro cielo y nuestro infierno. Un templo maya, una catedral medieval o un palacio barroco eran algo más que monumentos: puntos sensibles del espacio y el tiempo, observatorios privilegiados desde los cuales el hombre podía contemplar el mundo y el trasmundo como un todo. Su orientación correspondía a una visión simbólica del universo; la forma y disposición de sus partes abrían una perspectiva plural, verdadero cruce de caminos visuales: hacia arriba y abajo, hacia los cuatro puntos cardinales. Punto de vista total sobre la totalidad. Esas obras no sólo eran una visión del mundo, sino que estaban hechas a su imagen: eran una representación de la figura del universo, su copia o su símbolo. La técnica se interpone entre nosotros y el mundo, cierra toda perspectiva a la mirada: más allá de sus geometrías de hierro, vidrio o aluminio no hay rigurosamente nada, excepto lo desconocido, la región de lo informe todavía no transformada por el hombre (Los signos en rotación, 1965).

El joven George Santayana, intuyendo tal vez la sensibilidad negativa y los presentimientos de los modernos, afirma en su tesis doctoral (The Sense of Beauty, 1895) que la belleza (y la estética, que es una contemplación de ella) es un valor positivo, intrínseco. En efecto, para los simbolistas, decadentes y altruistas de la época lo fue. En cambio, pensaba que la moral (y la ética, que es el estudio de ella) era un valor negativo. "Morality has to do with the avoidance of evil and the pursuit of good: aesthetics, only with enjoyment.» La ética y la estética, podríamos decir, son los glóbulos rojos y los glóbulos blancos del ensayo, el género que más se ha esforzado por mantener su equilibrio en todas las épocas: la narrativa, el drama, la poesía, experimentan profundas crisis transforma- 
doras. E1 ensayo, no. Este florece o se disminuye; en la actualidad, por una disminución de la Persona en la literatura, simplemente se despla$\mathrm{za}^{4}$. Floreció en la Modernidad hispanoamericana a partir de la luminosa Visión de Anahuac (1917) de Alfonso Reyes; pero ya esa Modernidad ha llegado a su término y estamos en el trance de un nuevo movimiento, todavía sin nombre.

En conclusión, entre los Modernistas reinaba una conciencia alegórica y simbólica de la unidad. Fe estética, esperanza ética, lúdico porvenir. La inteligencia les salvaría. La obsesión por la belleza no excluía de sus sueños la justicia universal. En el fondo eran humanistas. Los modernos, posteriores, serían los desengañados; su obra, un asedio implacable a la Persona a través de los arquetipos americanos: Quetzalcoatl, los Señores de la Nada, Martí el mártir, la genealogía de los Buendía, el desierto, la pirámide, la Utopía amazónica. En 1940 Eduardo Mallea se pregunta (El sayal y la púrpura) «si no vivimos la epopeya de una sobreestructuración del conocimiento gratuito». La unidad se volvió dispersa. Lo concreto del pasado se transformó en lo abstracto del porvenir ${ }^{5}$. En el fondo eran escépticos y existencialistas. Tenía que ser así.

${ }^{4}$ Véase mi trabajo "On the Contemporary Displacement of the Hispanic American Essay», en Hispanic Review, XLVI (1978), núm. 3, pp. 329-341.

${ }^{5}$ Es, básicamente, la tesis de Carlos Fuentes en «De Quetzalcoatl al Pepsicoatl», en Tiempo mexicano (1971). 
